\title{
AVALIAÇÃO DO ESTADO NUTRICIONAL
}

\author{
ASSESSMENT OF THE NUTRITIONAL STATUS
}

Helio Vannucchi ${ }^{1}$, Maria do Rosário Del Lama De Unamuno², Julio Sergio Marchini ${ }^{1}$

Docente1; Enfermeira Unidade Metabólica² da Divisão de Nutrologia do Departamento de Clínica Médica da Faculdade de Medicina de Ribeirão Preto da Universidade de São Paulo.

Correspondência: Prof.Dr. Hélio Vannucchi, Divisão de Nutrologia do Departamento de Clínica Médica da Faculdade de Medicina de Ribeirão Preto - Campus Universitário - CEP: 14.048-900 - Ribeirão Preto - SP- Email: hvannucc@fmrp.usp.br

VANNUCCHI H; UNAMUNO M do R Del L de \& MARCHINI JS Avaliação do estado nutricional. Medicina, Ribeirão Preto, 29: 5-18, jan./mar. 1996.

RESUMO: A desnutrição é reconhecida como um dos principais problemas médicos, especialmente em países em desenvolvimento. Os métodos para avaliar o estado nutricional de indivíduos em grupos populacionais foram extensivamente tratados na literatura médica. $O$ objetivo principal desta revisão foi proporcionar uma análise crítica da avaliação nutricional bioquímica e antropométrica.

UNITERMOS: Antropometria. Avaliação. Estado Nutricional. Distúrbios Nutricionais.

\section{INTRODUÇÃO}

O interesse na avaliação do estado nutricional do paciente hospitalizado tem aumentado com a constatação de grande incidência de desnutrição entre os pacientes internados, na maioria dos hospitais e mostra-nos a associação entre desnutrição protéico-calórica (DPC) e a evolução clínica do paciente (interferindo no tempo de internação e número de complicações). A aplicação das técnicas de avaliação do estado nutricional revelou, por exemplo, que cerca de $50 \%$ dos pacientes admitidos em diferentes serviços intra-hospitalares, apresentaram graus variados de desnutrição.

Muitos dos pacientes que desenvolvem DPC são internados com história de perda de peso, resultante de anorexia e aumento do catabolismo associado ao trauma catabólico da cirurgia ou sepsis e medidas terapêuticas, comumente, usadas em determinadas situações (por exemplo, soro glicosado a 5\%).

A presença de DPC resulta em aumento significativo da incidência de mortalidade e morbidade no ambiente hospitalar. A perda de proteínas reduz a resistência à infecção, impede reparo de tecidos e interfere na síntese de enzimas e proteínas plasmáticas.

Uma das grandes preocupações da Nutrologia é estabelecer, precocemente, e com maior precisão o diagnóstico das alterações do estado nutricional. Sabe-se, entretanto, que a maior parte dos casos de alteração do estado nutricional apresenta-se sob a forma subclínica, exigindo do médico nutrólogo a utilização de todos os recursos disponíveis para o exame do paciente. Em circunstâncias adversas, o estado nutricional pode ser afetado por alterações na ingestão, na absorção, transporte, utilização, excreção e reserva dos nutrientes, resultando em desequilíbrio nutricional. Este, dependendo de sua intensidade e/ou duração pode comprometer o estado nutricional do organismo. Frequientemente, verifica-se distúrbios em mais de um destes fatores e assim alterações que, de acordo com a sua intensidade e duração, provocarão maiores ou menores sintomas e sinais clínicos.

É também muito importante o conhecimento dos mecanismos fisiopatológicos envolvidos na etiologia das alterações nutricionais que se processam em sequiência, 
com etapas comuns às doenças nutricionais. Qualquer que seja o fator causal de início, a alteração do estado de normalidade envolve modificações de reservas orgânicas. Se a causa persistir, a próxima etapa será o aparecimento de alterações bioquímicas e/ou metabólicas. Durante sua evolução, ocorrerão distúrbios funcionais que poderão se constituir em sintomas e, eventualmente, sinais, que são detectados no exame clínico. Esta etapa pode ser diferenciada como o início da fase clínica, sendo que as anteriores constituem a fase subclínica. Após essa fase, ocorrerão alterações anatômicas, clinicamente reconhecidas, algumas poderão ser reversíveis e outras evoluirão para a morte de órgãos com perda da função ou até de todo o organismo.

A avaliação nutricional é o primeiro passo no tratamento da desnutrição. Os dados mais importantes na avaliação são aqueles que refletem mais, adequadamente, o estado dos vários componentes da massa celular corpórea (Tabela I e II), fornecendo o nível das reservas nutricionais e da massa metabolicamente ativa.

Tabela I - Composição corporal de um homem referência de $70 \mathrm{~kg}$

\begin{tabular}{lc}
\hline Componentes & $\%$ de peso \\
\hline Gordura & 25 \\
Pele, esqueleto & 10 \\
Extracelular e proteína plasmática & 25 \\
Músculo esquelético e visceral & 40 \\
\hline
\end{tabular}

Tabela II - Termos relacionados à composição corporal

\begin{tabular}{ll}
\hline \multicolumn{1}{c}{ Termos } & \multicolumn{1}{c}{ Significado } \\
\hline Massa Gordurosa Corporal & $\begin{array}{l}\text { Quantidade de triglicérides no organismo } \\
\text { Gordura }(\sim 83 \%) \text { mais as estruturas de suporte celular e extracelulares } \\
\text { Massa Adiposa Tecidual }\end{array}$ \\
$\begin{array}{l}\text { (consistindo de 2\% proteína e 15\% de água) } \\
\text { Massa Corporal Magra }\end{array}$ & Massa Corporal não adiposa \\
Massa Livre de Gordura & Componentes celulares do organismo \\
Massa Celular Corporal & Minerais totais ósseos do organismo ( 85\% dos sólidos no esqueleto) \\
Sólidos Extracelulares &
\end{tabular}

\section{PARÂMETROS DE AVALIAÇÃO NUTRICIO- NAL: SINAIS CLÍNICOS, HISTÓRIA ALI- MENTAR, DADOS ANTROPOMÉTRICOS E DADOS BIOQUÍMICOS.}

\subsection{Sinais clínicos}

O reconhecimento dos sintomas e sinais clínicos de alteração do estado nutricional é de grande importância por se tratar de prática simples e econômica. Consiste em avaliar as manifestações que podem estar relacionadas com possível alimentação inadequada, evidenciando-se por meio de alterações de tecidos orgânicos, de órgãos externos como a pele, mucosas, cabelos e os olhos. Quando a carência se encontra, ainda, na fase inicial, torna-se difícil sua interpretação, o que torna a pratica limitada, impossibilitando sua utilização como único meio de diagnóstico precoce da desnutrição.

Para algumas carências nutricionais específicas, o exame clínico torna-se bastante objetivo, como no caso do bócio endêmico, do raquitismo, da hipovitaminose A com xeroftalmia e em outras situações de hi- povitaminose, como a pelagra. Vale ressaltar que alguns sinais clínicos não podem ser considerados específicos de determinadas carências nutricionais, visto que vários fatores não nutricionais podem produzir manifestações similares. Para fins diagnósticos, deve-se considerar o conjunto de sinais que caracterizam uma síndrome carencial. Os sinais clínicos de deficiências nutricionais devem ser confirmados com exames laboratoriais e dados alimentares (Tabela III).

\subsection{História alimentar}

A avaliação do estado nutricional do paciente deve ocorrer nas primeiras 24 horas de internação. Durante a anamnese alimentar, são pesquisadas as quantidades e qualidade de alimentos ingeridos, antes e durante a doença atual, bem como informações sobre perda de apetite, aversão por alimentos, náusea, vômito, alterações do trato digestivo (dificuldade de mastigação, azia, queimação, obstipação, diarréia e outros), abuso de bebidas alcoólicas e alterações no peso. Deve-se obter todas as informações que poderão contribuir para o estabelecimento da conduta terapêutica futura. 
Tabela III - Medidas de Composição Corporal

\begin{tabular}{|c|c|}
\hline Compartimentos & Métodos \\
\hline \multicolumn{2}{|l|}{ Técnicas Diretas de Medição } \\
\hline \multirow[t]{4}{*}{ Massa Corporal Magra / Massa corporal celular } & Nitrogênio Corporal Total (proteínas) \\
\hline & Análise de Ativação Neutrônica \\
\hline & $\begin{array}{l}\text { Potássio Total Corporal } 40 \mathrm{~K} \text { (endógeno) ou } 40 \mathrm{~K} \text { (administrado } \\
\text { ao paciente) }\end{array}$ \\
\hline & Água Intracelular: Água Corporal total menos a água extracelular \\
\hline $\begin{array}{l}\text { Gordura corporal ou } \\
\text { percentagem de gordura corporal }\end{array}$ & Densitometria: pesagem submersa \\
\hline Tecido Adiposo & $\begin{array}{l}\text { Tomografia computadorizada } \\
\text { Ressonância magnética } \\
\text { Ultra-sonografia }\end{array}$ \\
\hline Ossos / Sólidos extracelulares & $\begin{array}{l}\text { Calcio Corporal Total: Análise por Ativação Neutrônica } \\
\text { Massa Mineral Óssea Corporal Total }\end{array}$ \\
\hline \multicolumn{2}{|l|}{ Técnicas de medidas Indiretas } \\
\hline Gordura Corporal & Antropometria \\
\hline Massa Livre de Gordura & $\begin{array}{l}\text { Impedância Bioelétrica } \\
\text { Eletrocondutividade corporal total }\end{array}$ \\
\hline Massa Muscular & $\begin{array}{l}\text { Creatinina Urinária } \\
\text { 3-metilhistidina urinária } \\
\text { Antropometria }\end{array}$ \\
\hline
\end{tabular}

\subsection{Antropometria}

Antropometria é a medida das dimensões corpóreas. As medidas antropométricas mais empregadas na avaliação do estado nutricional são: peso, altura, circunferências (braço e cintura), comprimento do braço e pregas cutâneas (tríceps, bíceps, subescapular, suprailíaca). Através da combinação destas medidas podese calcular as relações peso/altura ${ }^{2}$ e a circunferência muscular do braço e o índice de gordura do braço.

As medidas antropométricas são fáceis de se realizar e, relativamente, sensíveis para avaliar isoladamente pacientes adultos hospitalizados quanto à desnutrição. O marasmo pode ser facilmente diagnosticado, pois caracteriza-se por diminuição dos parâmetros com preservação das proteínas plasmáticas até uma depleção grave. No kwashiorkor, existe líquido retido no organismo, que aparece como edema e/ou ascite. Neste tipo de desnutrição, o peso tem menor significado como critério de desnutrição. Já na presença de estado catabólico, secundário à cirurgia, politrauma, ou sepsis desenvolve-se profunda deficiência da proteína visceral, antes de perda significativa nos indicadores antropométricos.

\section{3.a. Peso e altura}

São as medidas mais utilizadas na avaliação nutricional pela fácil disponibilidade de equipamentos, determinação simples e precisa e boa aceitação pelos pacientes. Recomenda-se que a altura seja obtida estando o paciente de pé, encostado em um haste vertical inextensível (superfície lisa ou parede), nuca, nádegas e calcanhares devem tocar esta haste, estando o indivíduo descalço. Quanto ao peso, o sujeito deverá estar com o mínimo de roupa, sendo considerado o peso do período da manhã.

O Índice de Quelelet ou Índice de Massa Corporal (IMC), com a massa corporal expressa em quilogramas e a estatura em metros ${ }^{2}$, é aparentemente o de melhor correlação com massa corporal (valores do coeficiente de correlação "r", normalmente superiores a 0,80 ), e apresenta baixa correlação com a estatura (normalmente "r", em torno de 0,10). Estudos, com amostras representativas da população americana e de outros países do primeiro mundo, demonstram que o IMC correlaciona-se com a massa de gordura corporal (r, em torno de 0,90), com a dobra cutânea subescapular (r, em torno de 0,70$)$, com a dobra cutânea tricipital (r, acima de 0,60$)$, e com o percentual de gordura corporal (r, acima de 0,70$)$.

$$
\mathrm{IMC}=\frac{\text { Peso }(\mathrm{kg})}{\text { Estatura }^{2}(\mathrm{~m})}
$$


Não existe, ainda, uma definição clara dos limites de corte para caracterizar o estado nutricional. Um dos problemas é o fato de não se saber, claramente, como levar em consideração a idade, já que com o envelhecimento ocorre, simultaneamente, aumento na deposição de gordura e uma perda do tecido livre de gordura.

A utilização da terminologia proposta por Garrow (obesidade em graus), Tabela IV deve ser feita com cautela, já que, por definição, obesidade significa excesso de gordura corporal, o que, na verdade, não é medida através do IMC.

\begin{tabular}{lcc}
\multicolumn{3}{l}{$\begin{array}{l}\text { Tabela IV - IMC } \\
\text { mendado pela }\end{array}$} \\
\hline $\begin{array}{c}\text { Estado } \\
\text { Nutricional }\end{array}$ & $\begin{array}{c}\text { IMC } \\
\left(\mathrm{kg} / \mathrm{m}^{2}\right)\end{array}$ & $\begin{array}{c}\text { Grau de } \\
\text { Obesidade }\end{array}$ \\
\hline Baixo peso & $<20$ & 0 \\
Normal & 20 a 24,99 & 0 \\
Sobrepeso & 25 a 29,99 & I \\
Obesidade & $\geq 30$ & II \\
& $\geq 40$ & III \\
\hline
\end{tabular}

Outra proposta, sugerida para a definição de limites de corte, consiste na determinação de valores do IMC, correspondentes aos percentis 85 e 95 de uma faixa etária, para diagnosticar sobrepeso e obesidade, respectivamente (Tabela V).

\begin{tabular}{cc}
\multicolumn{2}{c}{ Tabela V - IMC - Ajuste por idade (Andres) } \\
\hline Idade (anos) & IMC $\left(\mathrm{kg} / \mathrm{m}^{2}\right)^{*}$ \\
\hline $19-24$ & $19-24$ \\
$25-34$ & $20-25$ \\
$35-44$ & $21-26$ \\
$45-54$ & $22-27$ \\
$55-64$ & $23-28$ \\
$\geq 65$ & $24-29$ \\
\hline
\end{tabular}

* Estes são os intervalos de normalidade, segundo a faixa etária. Será considerado com sobrepeso o indivíduo que apresentar IMC até $20 \%$, acima do limite superior dos intervalos de normalidade, e a partir de $20 \%$, acima destes intervalos, será considerado obeso (a).
A Organização Mundial da Saúde (OMS) sugere os valores de IMC entre 16 e 18,4 para indicar os graus 1 e 2 de DPC.

Os dois extremos de IMC estão associados, com maior risco de morbidade e mortalidade. As causas de morte, associadas com IMC baixo, foram tuberculose, câncer pulmonar e doenças pulmonares obstrutivas, enquanto as causas de mortalidade, associadas com IMC alto, foram doenças cardiovasculares, diabetes para homens e câncer do cólon.

Quando possível, levar em conta o peso habitual e o peso atual, a diferença entre esses valores e o tempo durante o qual se estabeleceu a perda de peso. $\mathrm{O}$ peso atual pode ser expresso como porcentagem do peso habitual:

$$
\% \text { do peso habitual }=\frac{\text { Peso atual }}{\text { Peso habitual }} \times 100
$$

As alterações têm maior significado, quando recentes e relacionadas com processos mórbidos. Variações superiores a $10 \%$ podem sugerir desnutrição. A porcentagem de alteração é expressa pela fórmula:

$$
\text { Alteração do peso (\%) } \frac{\text { Peso habitual - Peso atual }}{\text { Peso habitual }} \times 100
$$

Blackburn e col. apresentam a seguinte Tabela VI, quanto à variação de peso:

Tabela VI - Variação de peso em função do tempo

\begin{tabular}{lc}
\hline \multicolumn{1}{c}{ Tempo } & Perda de peso significativa \\
\hline 1 semana & $1-2 \%$ \\
1 mês & $5 \%$ \\
3 meses & $7,5 \%$ \\
6 meses & $10 \%$ \\
\hline
\end{tabular}

\section{3.b. Pregas cutâneas}

A depleção grave dos estoques de gordura nos pacientes representa um problema nutricional significativo pois pode interferir com os mecanismos adaptativos de utilização de gordura, como combustível endógeno em estados de inanição ou semi-inanição.

A medição das pregas cutâneas constitui o meio mais conveniente para estabelecer, indiretamente, a 
massa corpórea de gordura. Através da somatória das pregas (tríceps, bíceps, subescapular, supra-ilíaca), obtém-se a porcentagem de gordura corporal com o auxílio de uma equação de regressão linear. A medida isolada da prega cutânea do tríceps proporciona uma estimativa das reservas gordurosas do subcutâneo, a qual relaciona-se com o volume de gordura do organismo.

A prega cutânea deve ser medida com adipômetro que mantenha pressão constante, não servem, portanto, os que não possuem mecanismos reguladores de pressão. O procedimento que se segue é usado para medir a prega cutânea sobre o tríceps do braço não dominante: 1) pedir à pessoa que deixe o braço solto e relaxado; 2) com uma fita métrica, medir o comprimento entre o processo acromial da escápula e o olécrano, e marcar este ponto médio; 3) aproximadamente $2 \mathrm{~cm}$ acima deste ponto, pinçar a pele sobre o tríceps, entre o polegar e o indicador; 4) puxar a pele ligeiramente, afastando-a do músculo; 5) suavemente, pinçar a pele entre as extremidades do adipômetro, no ponto marcado; 6) ler a medida que o adipômetro acusa em $\mathrm{mm}$.

A prega cutânea bicipital é obtida na parte média do braço sobre o bíceps. A prega cutânea subescapular é medida $1 \mathrm{~cm}$ abaixo do ângulo inferior da escápula, com o braço em extensão. A prega cutânea supra-ilíaca é medida na linha axilar média, com o tronco estendido, $1 \mathrm{~cm}$ acima da crista ilíaca anterior superior.

Paiva e col.(1992) em estudo para avaliar o uso das pregas cutâneas e da circunferência muscular do braço, para diagnosticar DPC, encontraram eficiência limitada das pregas cutâneas (PT e PSE) e da circunferência muscular do braço, em pacientes adultos hospitalizados. Para esta finalidade as pregas parecem ser mais sensíveis, quando medidas em pacientes com menos de 50 anos de idade e a circunferência muscular do braço, em pacientes do sexo masculino.

A soma dos valores das pregas (S) cutâneas tricipital, bicipital, supra-ilíaca e subescapular, em mm, permite fazer uma extrapolação da gordura corpórea, porcentagem de gordura - $\mathrm{F}(\%)$ - por meio da fórmula:

$$
\begin{aligned}
& \text { Homens (adultos): } F(\%)=\frac{495+450 \times(0,0632 \log S-1,1610)}{1,1610-0,0632 \log S} \\
& \text { Mulheres (adultas): } F(\%)=\frac{495+450 \times(0,0720 \log S-1,1581)}{1,1581-0,0720 \log S}
\end{aligned}
$$

Tem sido registrado que a área adiposa do braço $(\mathrm{AAB})$ pode representar, matematicamente, melhor o comprometimento do tecido adiposo em situações de déficit de energia e proteínas. A área adiposa do braço pode ser calculada pela fórmula:

$$
\mathrm{AAB}=\frac{\mathrm{PT} \times \mathrm{CB}}{2}-\frac{\pi \times \mathrm{PT} 2}{4}
$$

A prega tricipital, como indicador do estado nutricional, tem sido empregada de acordo com uma abordagem normativa onde comparam-se os valores de um indicador, verificados na população normal conhecida, aos obtidos em uma população desconhecida. Valores "anormais" são aqueles que se situam fora do âmbito dos valores da população normal. No caso da prega tricipital, os valores observados são cotejados contra valores padrões, referidos por Jelliffe ou Blackburn e cols. ou Frisancho. O diagnóstico de desnutrição é baseado no achado de valores menores que um determinado valor, o qual é determinado "ponto de corte". Blackburn e cols. propõem, como ponto de corte indicativo de desnutrição, valores abaixo do quinto percentil do padrão de referência, como foi estabelecido a partir dos dados obtidos em grande pesquisa populacional americana (Ten State Nutrition Survey).

A avaliação da gordura do corpo, a partir da medida das pregas cutâneas, não é isenta de críticas. Em primeiro lugar, este procedimento baseia-se nas suposições de que o tecido adiposo subcutâneo representa proporção constante da gordura total do corpo e que, no local escolhido para a medida, a espessura do tecido representa a espessura média do tecido gorduroso subcutâneo.

\section{3.c. Circunferência do braço $(\mathrm{CB})$ e Cir- cunferência muscular do braço $(\mathrm{CMB})$}

Durante inanição e estresse prolongado, as reservas protéicas são mobilizadas para atender a demanda da fase aguda e proteínas secretoras, levando à depleção da massa corpórea magra. $\mathrm{A} \mathrm{CMB}$ é usada para avaliar este compartimento. Já a CB reflete a composição corpórea total sem distinguir tecido adiposo e massa magra.

A CB é obtida no ponto médio do braço, estando este estendido, não dominante, e no mesmo local onde foi obtida a PT. No caso de pacientes internados, utiliza-se o braço que for possível medir. 
A CMB é calculada a partir da PT e CB pela seguinte fórmula:

$$
\mathrm{CMB}=\mathrm{CB}-3,14 \times \mathrm{PT}
$$

$\mathrm{CMB}=$ Circunferência muscular em $\mathrm{cm}$

$\mathrm{CB}=$ Circunferência braquial em $\mathrm{cm}$

$\mathrm{PT}=$ Prega tricipital em $\mathrm{cm}$

Da mesma maneira que a prega tricipital, não há dados disponíveis sobre a distribuição dos valores da CB e CMB na população brasileira adulta. Existem, porém dados relacionados a grupos populacionais menores e definidos. A observação de dados brasileiros de CMB parecem mostrar a tendência dos valores dos homens se distanciarem mais (situam-se mais à esquerda, valores entre o percentil 5 e o percentil 30) em relação aos padrões dos EUA, do que os valores das mulheres. Quanto às mulheres, as diferenças entre o padrão dos EUA são menores; há até grupos em que os valores são iguais ou maiores. Valores maiores da CMB foram encontrados em grupos de indivíduos que têm maior atividade física, como os trabalhadores rurais e os atletas. Blackburn propõe o percentil 5 como ponto de corte indicativo de desnutrição, como estabelecido no Ten State Nutrition Survey. Como padrões de referências internacionais, dispomos da tabela de Frisancho e Jelliffe.

Tem sido proposta a área muscular do braço, como medida teórica mais correta para a avaliação indireta da massa muscular. A fórmula a ser aplicada é:

$$
\text { Área muscular }=\frac{(\mathrm{CB}-\mathrm{PT} \times \pi)}{4 \pi} 2
$$

Esta apresenta as limitações que decorrem da própria variabilidade dos dados antropométricos, de fatores relacionados à sua mensuração e às características locais do tecido, onde as medidas são feitas.

\section{3.d. Índice de gordura do braço}

É definido como o quociente da medida da prega tricipital (em mm) e a distancia olécrano-acromial $\left(\mathrm{em} \mathrm{dm}{ }^{2}\right)$. Esta medida apresenta uma correlação positiva quando se compara ao índice de massa corporal, e está indicada como medida antropométrica sempre que a medição da altura e do peso não for possível em pacientes hospitalizados (pacientes sem condições de sair do leito). Deve ser utilizada como medida seqüencial na avaliação do estado nutricional. Os valores seguintes foram encontrados no Hospital das Clínicas de Ribeirão Preto (Tabela VII).

\begin{tabular}{lrc}
\multicolumn{3}{l}{$\begin{array}{l}\text { Tabela VII - Índice de Gordura do Braço em vá- } \\
\text { rias situações clínicas (Média } \pm \text { DP) }\end{array}$} \\
\hline \multicolumn{2}{c}{ Homens } & Mulheres \\
\hline Controles normais $0,78 \pm 0,28$ & $1,49 \pm 0,39$ \\
Obesidade & $1,93 \pm 0,75$ & $2,98 \pm 0,67$ \\
DPC & $0,37 \pm 0,22$ & $0,53 \pm 0,27$ \\
\hline
\end{tabular}

\section{AVALIAÇÃO BIOQUÍMICA DO ESTADO NUTRICIONAL}

$\mathrm{Na}$ avaliação do estado nutricional, as determinações bioquímicas são usadas como complemento dos dados de história, exame físico e antropométrico. $\mathrm{Na}$ prática clínica, são empregadas determinações urinárias de creatinina, hidroxiprolina e 3-metilhistidina e plasmáticas de aminoácidos, transferrina, albumina, minerais e vitaminas. Essas determinações urinárias visam, em geral, correlacionar um dos compartimentos orgânicos, por exemplo massa muscular magra, com os resultados obtidos. Assim sendo, tanto a creatinina, como a 3-metilhistidina, que são produtos finais do metabolismo protéico, dão uma idéia da massa muscular do indivíduo.

A disponibilidade de vitaminas e minerais pelo organismo, também, é avaliada por determinações bioquímicas.

Várias medidas bioquímicas têm sido propostas, objetivando a detecção precoce de deficiências protéicas subclínicas e marginais. Pesquisas realizadas na avaliação nutricional de pacientes, e em estudos populacionais, têm consagrado a utilidade de alguns deste indicadores bioquímicos, bem como apontado a ineficácia de outros. Por exemplo, a albumina tem sido consagrada como bom indicador diagnóstico das formas graves de desnutricão, porém com baixa sensibilidade diagnóstica nos estágios iniciais de DPC. O mesmo pode ser afirmado para a proteinemia total. (Tabela VIII). 


\section{Tabela VIII - Medidas bioquímicas do estado nutricional}

\begin{tabular}{|c|c|c|}
\hline NUTRIENTE & MAIS SENSÍVEL & MENOS SENSÍVEL \\
\hline Proteína & $\begin{array}{l}\text { Aminoácido no plasma } \\
\text { Albumina sérica } \\
\text { Elevação da creatinina urinária }\end{array}$ & Proteína sérica total \\
\hline Lípides & $\begin{array}{l}\text { Colesterol sérico } \\
\text { Triglicérides séricos } \\
\text { Lipoproteínas }\end{array}$ & \\
\hline Vitamina A & $\begin{array}{l}\text { Vitamina A sérica } \\
\text { Caroteno sérico }\end{array}$ & \\
\hline Vitamina D & 25-OH-vitamina D3 & Cálcio sérico \\
\hline & Fosfatase alcalina & Fósforo sérico \\
\hline Vitamina $\mathrm{E}$ & $\begin{array}{l}\text { Teste de hemólise de hemácias } \\
\text { com peróxido de hidrogênio } \\
\text { Tocoferol sérico ou plasmático }\end{array}$ & \\
\hline Vitamina $\mathrm{K}$ & & Tempo de protrombina \\
\hline Tiamina & $\begin{array}{l}\text { Tiamina urinária } \\
\text { Atividade de transcetolase ertitrocitária }\end{array}$ & Piruvato sangüíneo \\
\hline Riboflavina & $\begin{array}{l}\text { Riboflavina urinária } \\
\text { Redutase glutadiona eritrocitária }\end{array}$ & \\
\hline Niacina & $\mathrm{N}^{1}$-metil-nicotinamida na urina de 24 horas & Piridona urinária(24 horas) \\
\hline Vitamina B6 & $\begin{array}{l}\text { Teste de sobrecarga de triptofano (mg de } \\
\text { ácido xanturênico excretado na urina) }\end{array}$ & $\begin{array}{l}\text { Excreção de piridoxina urinária } \\
\text { (microg/g de creatinina) } \\
\text { Transaminase sangüínea }\end{array}$ \\
\hline Ácido Fólico & Folato da hemácia & $\begin{array}{l}\text { Folato sérico } \\
\text { Mielograma } \\
\text { Hemograma } \\
\text { Excreção urinária de FIGLU }\end{array}$ \\
\hline Vitamina $\mathrm{B}_{12}$ & $\begin{array}{l}\text { B12 sérica } \\
\text { Timidilato sintetase sérico } \\
\text { Ácido metilmalônico urinário }\end{array}$ & $\begin{array}{l}\text { Mielograma } \\
\text { Hemograma } \\
\text { Teste de Schilling }\end{array}$ \\
\hline Vitamina C & Ácido ascórbico sérico & Ácido ascórbico urinário \\
\hline Ferro & $\begin{array}{l}\text { Depósitos de ferro na medula óssea } \\
\text { Ferro sérico } \\
\text { Saturação de transferrina \% }\end{array}$ & $\begin{array}{l}\text { Hemoglobina } \\
\text { Hematócrito } \\
\text { Hemograma }\end{array}$ \\
\hline lodo & & $\begin{array}{l}\text { lodo urinário } \\
\text { Teste de função da Tireóide }\end{array}$ \\
\hline Zinco & Zinco plasmático ou sérico & Zinco leucocitário \\
\hline Magnésio & Magnésio sérico & \\
\hline
\end{tabular}




\subsection{Proteínas plasmáticas}

\section{1.a. Albumina}

Dentre as proteínas de transporte presentes no plasma, a albumina tem sido a mais freqüentemente utilizada na avaliação do estado nutricional. Segundo alguns autores, a albuminemia reflete as reservas protéicas viscerais, distintas das proteínas somáticas, representadas pela massa protéica muscular esquelética. Assim, pode haver queda das primeiras, enquanto que as reservas somáticas permanecem dentro dos limites normais. Isto ilustra a grande sensibilidade da síntese de albumina ao conteúdo protéico da dieta.

Embora a hipoalbuminemia tenha sido considerada a anormalidade bioquímica mais consistentemente confirmada em crianças com deficiência protéica grave (kwashiorkor clássico), tais reduções não são tão significativas no marasmo. Nesta situação, são preservadas as funções vitais de tecidos considerados essenciais. A criança marasmática consome seus próprios tecidos como fonte de nutrientes para a homeostase energética.

O principal fator da baixa sensibilidade da albumina no diagnóstico da fase aguda da DPC, talvez seja a sua meia vida biológica relativamente longa $( \pm 20$ dias), podendo transcorrer várias semanas para que ocorra uma resposta às variações na ingestão dietéticoprotéica. A grande massa corporal de albumina, também, merece destaque como fator de resistência dos seus níveis circulantes à ingestão alimentar. Fatores não nutricionais podem afetar seus valores. Assim, situações que alterem o compartimento hepático de substratos protéicos ou energéticos, bem como cofatores, como o zinco, comprometem a albuminemia, o que pode ser visto na infecção, trauma cirúrgico, lesão tecidual, enteropatias exsudativas, doenças hepáticas e insuficiência cardíaca.

Blackburn e Harvey referem que albuminemia, em níveis menores que $3,5 \mathrm{mg} / \mathrm{dl}$, sugerem início de desnutrição e nível menor que $3 \mathrm{mg} / \mathrm{dl}$ representa depleção significativa. O ICNND (Interdepartmental Committee on Nutrition for National Defense) estabeleceu as seguintes graduações e interpretações para os níveis de albumina: $\langle 2,8 \mathrm{mg} / \mathrm{dl}=$ deficiente; $2,80-3,49 \mathrm{mg} / \mathrm{dl}=$ baixo e $>3,5 \mathrm{mg} / \mathrm{dl}=$ aceitável.

\section{1.b.Transferrina}

É uma beta-globina de síntese hepática, transportadora do ferro sérico. A transferrina, também, tem sido proposta como proteína plasmática útil na avalia- ção do estado nutricional. A principal vantagem em relação à albumina é a sua meia vida biológica curta, cerca de 8 dias, o que a torna mais susceptível às alterações no processo de síntese protéica.

O resultado de sua dosagem pode ser mascarado por vários fatores que afetam (aumentam) sua síntese hepática, tais como deficiência de ferro e infecção. Esta limitação pode ser ampliada para outras patologias como doenças hepáticas, renais, de medula óssea, insuficiência cardíaca congestiva e inflamações generalizadas.

Níveis de transferrina sérica, inferiores a $170 \mathrm{mg} / \mathrm{dl}$, podem ser considerados como indicativos de deficiência protéica moderada, enquanto níveis inferiores a $150 \mathrm{mg} / \mathrm{dl}$ correspondem à deficiência grave. Pode ser estimada, indiretamente, pela fórmula:

Transferrina $(\mathrm{mg} / 100 \mathrm{ml})=($ TIBC $\times 0,8)-43$

3.1.c. Proteína Ligadora do Retinol (RBP) e Pré-albumina que se liga à Tiroxina (TBPA)

A RBP, por apresentar a meia vida de apenas algumas horas (12 horas), e a TBPA meia vida de 2 dias, têm sido sugeridas como indicadores mais sensíveis, principalmente no reconhecimento do estágio agudo de DPC.

Além da deficiência protéica, dentre os demais fatores determinantes da diminuição do sistema de transporte do retinol plasmático estão as doenças hepáticas, hipotireoidismo, fibrose cística do pâncreas, etc. Em pacientes, com insuficiência renal crônica, são descritos níveis elevados tanto de RBP, como dos parâmetros relacionados com deficiência energética, vitamina A e zinco.

\section{1.d. Índice Creatinina Altura (ICA)}

Sabendo que cerca de $80 \%$ do músculo é constituído por água e $20 \%$, por proteína, um homem de $70 \mathrm{~kg}$ teria de 4 a $6 \mathrm{~kg}$ de proteína. $\mathrm{O}$ conhecimento deste compartimento muscular é importante na avaliação nutricional, com relação a proteínas do indivíduo.

Considerando que: 1) a creatinina se encontra quase que, totalmente, dentro do músculo esquelético; 2) em uma dieta livre de creatinina, o "pool" de creatinina total e a concentração média de creatinina por $\mathrm{kg}$ de músculo permanecem constante; 3) a creatinina é convertida, irreversivelmente, em taxa diária constante, independente de enzimas; 4) a creatinina, uma vez formada, é excretada via renal a uma taxa constante, conclui-se que esta excreção urinária de creatinina pode ser relacionada com a massa muscular do 
indivíduo.

O ICA é calculado como uma porcentagem do padrão, através da divisão da excreção da creatinina urinária, por um valor padrão para a altura do paciente. O ICA menor que $60 \%$ do padrão identifica paciente com risco aumentado para anergia, sepsis e morte.

$$
I C A=\frac{\text { Excreção de creatinina na urina em } 24 \text { horas }}{\text { Excreção teórica de creatinina em } 24 \text { horas }} \times 100
$$

A excreção teórica de creatinina na urina de 24 horas:

- homens - $23 \mathrm{mg}$ por $\mathrm{kg}$ de peso ideal

- mulheres - $18 \mathrm{mg}$ por $\mathrm{kg}$ de peso ideal

A confiabilidade nas determinações da creatinina urinária é maior quando as amostras são colhidas com rigor, e a técnica é, particularmente, útil para medidas de controle da evolução em um mesmo paciente.

\subsection{Impedância Bioelétrica}

Obtida por aparelho portátil que mede a impedância ou resistência do corpo à passagem de uma corrente elétrica, através de eletrodos de eletrocardiograma, colocados sobre a mão e o pé do paciente. Essa determinação demora apenas alguns segundos e não exige que o paciente tire suas roupas. A impedância bioelétrica baseia-se no princípio de que a resistência é inversamente proporcional à água corpórea total, através da qual a corrente se transmite. As medidas de impedância tem sido correlacionadas, satisfatoriamente com a água corpórea total, obtida por outros métodos.

\subsection{Outras técnicas}

A tomografia computadorizada e a ressonância magnética nuclear podem diferenciar entre os tecidos com e sem gordura do corpo. Já que estas técnicas visuais produzem dados de áreas localizadas do corpo, provavelmente elas são mais úteis na quantificação da distribuição regional da gordura do que na determinação da composição corpórea total.

A análise da ativação neutrônica é uma técnica que envolve a irradiação do corpo com um feixe de nêutrons e, assim, elevando os níveis energéticos de certos átomos. Depois, esses átomos emitem padrões energéticos distintos, tornando possível quantificar a concentração de nitrogênio, cálcio ou outros átomos do corpo (ver Tabelas).

A composição corpórea pode ser avaliada, também, por absorviometria fotônica dual corpórea, determinação do peso subaquático e eletrocondutibilidade corpórea total.

Vários parâmetros têm sido propostos e utilizados no sentido de se conhecer as condições nutricio- nais, alguns simples, outros sofisticados e dispendiosos. A experiência tem mostrado que nenhum parâmetro isoladamente define o estado nutricional e que um conjunto bem definido e padronizado de parâmetros permite razoável definição e, principalmente, possibilita, através da repetição das medidas, um controle da eficiência da terapêutica nutricional. Na interpretação dos dados deve-se lembrar que estes fazem parte de um contexto clínico.

\subsection{Minerais}

Um grande número de minerais são reconhecidos como essenciais para manter a vida. Podemos classificá-los em 2 grandes grupos, sendo a quantidade encontrada no organismo o marco divisor. Os oligoelementos são encontrados em quantidade menores que $100 \mathrm{mg} / \mathrm{kg}$ de peso corpóreo total (Fe, $\mathrm{Zn}, \mathrm{Cu}, \mathrm{Mn}$, $\mathrm{Cr}$, Mo, Se, F, I, etc). Na avaliação do estado nutricional dos minerais, vários fatores são considerados, como, por exemplo, edema e função renal. Para alguns, o $\mathrm{Mg}$ e o $\mathrm{P}$ diminuem a sua excreção urinária com a menor oferta. Por outro lado, em estado hipercatabólicos há aumento da excreção urinária de zinco.

Níveis séricos de alguns minerais, também, podem ser usados, Entretanto, causas inespecíficas como traumas podem originar menor valor plasmático e falsear os resultados.

\subsection{Vitaminas}

As necessidades diárias de diferentes vitaminas variam grandemente, por exemplo, a dose de Vitamina C é 50 mil vezes maior que a de Vitamina B12. Em geral, a avaliação do estado vitamínico é feita de 2 maneiras: pelos seus níveis plasmáticos e/ou pela medida da atividade enzimática que tem a vitamina como co-fator.

Os níveis séricos de $\beta$ caroteno, vitamina C, B12 e de folato refletem ingestão diária recente, enquanto as concentrações de Vitamina $C$ do leucócito e de folato das hemácias indicam o estado das reservas corpóreas. A vitamina B1 é estimada pela medida da atividade da transcetolase das hemácias e a vitamina B6 pela atividade da enzima aspartato transaminase, também, da hemácia. Alguns fatores de coagulação são dependentes da vitamina $\mathrm{K}$.

É importante ressaltar que o diagnóstico clínico das alterações do estado nutricional deve ser conseguido com a utilização plena das etapas que compõem o exame do paciente, ou seja, a história da moléstia atual, os antecedentes, o histórico alimentar, o exame físico completo, (ver Tabela IX) os dados antropométricos e laboratoriais. Outro aspecto é o erro da supervalorização de um dado isolado que pode levar a conclusões e decisões inadequadas e, portanto, deve ser evitado 


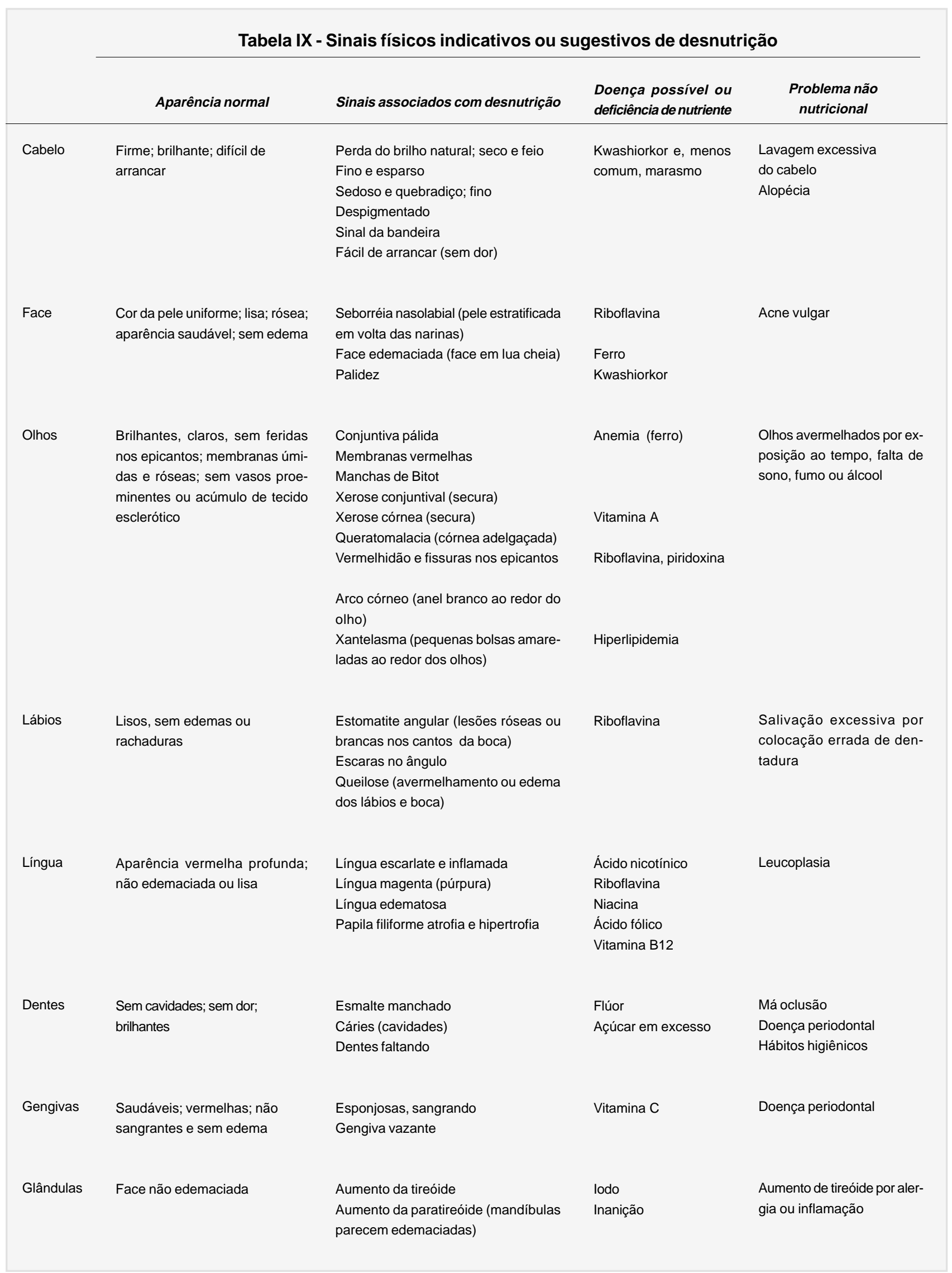




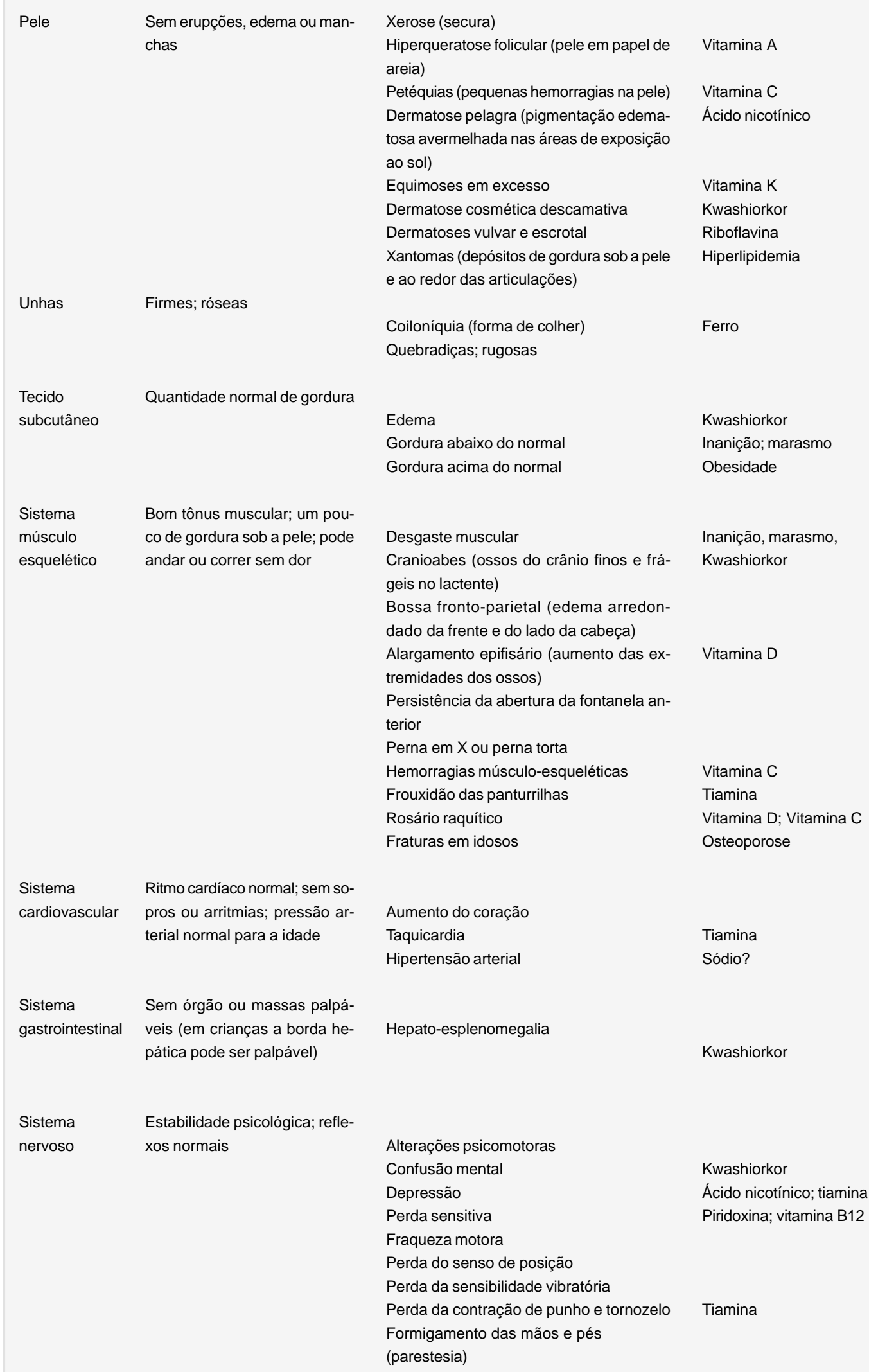

Exposição ambiental

Traumas físicos 


\section{CONCLUSÃO}

Após a avaliação nutricional, com a tabulação dos resultados, em geral, pode-se classificar os indivíduos em eutróficos, marasmáticos, "kwashiorkor" e obesos, em relação ao metabolismo energético-protéi- co. A Tabela $\mathrm{X}$ mostra um exemplo de resultados encontrados em indivíduos avaliados no Hospital das Clínicas de Ribeirão Preto. Entre uma situação e outra existe uma gama de variações que devem ser analisadas, criteriosamente, e cada caso individualmente.

Tabela X - Exemplos de avaliação nutricional antropométrica bioquímica, encontrada em diferentes situações

\begin{tabular}{lccccc}
\hline \multirow{2}{*}{ PARÂMETROS } & EUTROFIA & ATLETA & OBESO & KWASHIOKOR & MARASMO \\
\cline { 2 - 6 } & \multicolumn{5}{c}{ Sexo } \\
\cline { 2 - 6 } & Masculino & Masculino & Feminino & Masculino & Feminino \\
\hline Altura - m & 1,70 & 1,68 & 1,60 & 1,73 & 1,58 \\
Peso - kg & 63 & 62 & 90 & 60 & 40 \\
Peso/Alt. ${ }^{2}-\mathrm{kg} / \mathrm{m}^{2}$ & 22 & 22 & 35 & 20 & 16 \\
Circunferência braquial - cm & 28 & 28,4 & 50 & 27 & 18 \\
Prega Tricipital - mm & 12 & 13,0 & 40 & 10 & 2 \\
Circunferência muscular - cm & 24 & 24 & - & - & 15 \\
Creatinina urinária - mg/d & 1400 & 1550 & 800 & 500 & 400 \\
Índice Creatinina/Altura & 0,92 & 1,08 & 0,83 & 0,33 & 0,42 \\
Albumina Sérica - g/100ml & 4,0 & 4,2 & 3,9 & 1,8 & 3,0 \\
Transferrina Sérica - mg/100ml & 280 & 270 & 250 & 100 & 90 \\
\hline
\end{tabular}

VANNUCCHI H, De UNAMUNO M do R Del L MARCHINI JS Assessment of the nutritional status. Medicina, Ribeirão Preto, 29: 5-18, jan./mar. 1996.

ABSTRACT: Malnutrition is recognized as one of the major medical clinical problem, especially in developing countries. The means to assess the nutricional status of individuals or population groups have been extensively discussed in medical literature. The main objective of this review is providing a critical analysis of anthropometric and biochemical nutritional evaluation.

UNITERMS: Anthropometry. Evaluation. Nutritional Status. Nutritional Disorders.

\section{BIBLIOGRAFIA CONSULTADA}

1 - ALENCAR FH, SOUZA N, BURINI RC. Uso dos níveis plasmáticos de albumina, Transferrina e proteína ligadora do retinol (RBP) como parâmetros indicativos do estado nutricional. Recomendações e limitações. Rev Bras Nutr Clin, 4: 1-15, 1989.

2 - ANJOS LA. Índice de massa corporal como indicador do estado nutricional de adultos: revisão de literatura. Rev Saúde Pública 26: 431-436, 1992.

3 - ANSELMO MAC et al. Avaliação do estado nutricional Métodos bioquímicos. Rev Soc Bras Nutr Parenter 2: 11-17, 1985.
4 - AWAI M \& BROWN EB. Studies of the metabolism of 131 Ilabelled human transferrin. J Lab Clin Med 61:363, 1963.

5 - BISTRIAN BR et al. Prevalence of malnutrition in general medical. JAMA 235: 1567-1570, 1976.

6 - BLACKBURN GL \& HARVEY KB. Nutritional assessment as a routine in clinical medicine. Postgrad Med 71: 46-63, 1982.

7 - BOROUJERDI M \& MATTOCKS AM. Metabolism of creatinine In vivo. Clin Chem 29: 1363, 1983.

8 - BUTTERWORTH CE \& BLACKBURN GL. Hospital malnutrition. Nutr Today 10:8, 1975. 
9 - CAHILL Jr GL. Starvation in man. N Engl J Med 282:668, 1970

10 - DALE G et al. The effect of surgical operation on venous plasma amino acids. Surgery 81:295, 1977.

11 - DURNIN JVGA \& RAHAMAN MN. The assessment of the amount of fat in the human body from measurements of skinfold thickness. Br J Nutr 21:681, 1967.

12 - DUTRA DE OLIVEIRA JE; PEARSON WN \& DARBY WJ Clinical usefulness of the oral ascorbic acid tolerance test in scurvy. Am J Clin Nutr 7:630, 1959.

13 - FELL GS \& BURNS RR. Zinc and other elements. In: Johsnton IDA, ed. Advances in parenteral nutricion. MTP Press Lancaster, p. 241, 1978.

14 - FRISANCHO AR. New norms of upper limb fat muscle areas for assessment of nutritional status. Am J Clin Nutr 34: 2540-255, 1981.

15 - GAMBLE KC et al. Hospital-associated malnutrition: A reevaluation 12 years later J Am Diet Ass 93: 27-33, 1993.

16 - GOLDEN MHN; GOLDEN BE \& JACKSON AA Albumin and nutricional oedema. Lancet 1:114, 1980.

17 - GOODE AW The scientific basis of nutritional assessment J Anaesth 53:161, 1981.

18 - GRAY DS. Diagnóstico e prevalência da obesidade. Clín Méd Am Norte 1: 1-15, 1989.

19 - GURNEY JM \& JELLIFFE DB Arm anthropometry in nutritional assessment: nomograma for rapid calculation of muscle circunference and cross-sectional muscle and fat areas. Am J Clin Nutr 26:912, 1973.

20 - HAVERBERG LN et al Nt - methilhistidine content of mixed proteins in various rat tissues. Biochem Biophys Acta 405:67, 1975.

21 - HEYMSFIELD MD, et al. Measurement of muscle mass in humans: vality of the 24 hour urinary creatinine method. Am J Clin Nutr 37: 478-479, 1983.

22 - INGENBLEEK $Y$ et al Albumin, transferrin and the thyroxine binding prealbumin / retinol binding protein (TBPA - RBP) complex in assessment of malnutrition. Clin Chem Acta 63: 61-67, 1975.

23 - INSTITUTO NACIONAL DE ALIMENTAÇÃO E NUTRIÇÃO. Pesquisa nacional de saúde e nutrição: Condições nutricionais da população brasileira - adultos e idosos. Brasília, 1990.

24 - INTERDEPARTMENTAL COMMITEE ON NUTRITION FOR NATIONAL DEFENSE. Manual for Nutrition Surveys 2. ed Washington, 1963, p. 237.

25 - JELLIFFE DB. Evaluation del estado de nutrición de la comunidad. OMS Genebra, 1968.

26 - JENSEN MD. Research techniques for body composition assessment. Perspect Prat 92: 454-460, 1992
27 - KAY RG et al A syndrome of acute zinc deficiency during total parenteral alimentation in man. Ann Surg 183:33, 1976.

28 - KEYS, A. Recommendations concerning body measurements for the characterization of nutritional status. Hum Biol 28:111, 1956.

29 - KRAUSE MV \& MAHAN LK. Avaliação do estado nutricional. Roca, São Paulo, cap. 11, p.247-268, 1985: ALIMENTOS, NUTRIÇÃO E DIETOTERAPIA

30 - LAW DK; DUDRICK SL \& ABDOU NI. The effect of proteincalorie malnutrition on immune competence. Surg Ginecol Obstet 139:257, 1974.

31 - LINDSTEDT S \& PROCKOP DJ. Isotopic studies on urinary hydroxyproline as evidence for rapidly catabolized forms of collagen in the young rat. J Biol Chem 236:1399, 1961.

32 - MILLER Jr AT \& BLYTH CS. Estimation of lean body mass and body fat from basal oxygen consumption and creatinine excretion. J Appl Physiol 5:73, 1952.

33 - MULLEN JL. et al Implications of malnutrition in the surgical patient. Arch Surg 114:121, 1979.

34 - MUNRO HN; YOUNG VR. Urinary excretion of Nt methylhistidine (3-methylhistidine): a tool to study metabolic responses in relation to nutrient and hormonal status in health and disease of man. Am J Clin Nutr 31:1608, 1978.

35 - PAIVA SAR et al. O uso das pregas cutâneas e da circunferência muscular do braço no diagnóstico de desnutrição energético-proteica em pacientes adultos: Estudo crítico. Rev Hosp Clin Fac Med São Paulo, 47:223-30, 1992.

36 - PICOU D; ALLYNE GAO \& SEAKINS A. Hydroxiproline and creatinine excretion in infantile protein malnutrition. Clin Sci 29:517, 1965.

37 - SAUBERLICH HE; DOWDY ROPO \& SKALA JH. Laboratory tests for the assessment of nutritional status. CRC press Cleveland, Ohio, 1974

38 - SHENKIN A. Assessment of nutricional status: The biochemical approach and its problems in liver disease. J Human Nutr 33:341, 1979.

39 - SHETTY PS et al. Rapid turnover transport protein: an index of subclinical protein energy malnutricion. Lancet 2:230, 1979.

40 - SMILEY JD \& ZIFF M Urinary hydroxiproline excretion and growth. Physiol Rev 44:30, 1964.

41 - THOMAS AE; McKAY DA \& CUTLIP MB. A nomograph method for assessing body weight. Am J Clin Nutr 29:302, 1976.

42 - TWOMEY P; ZIEGLER MA \& ROMBEAU J. Utility of skin testing in nutricional assessment: a critical review. J. Parenter Enteral Nutr 6:50, 1982.

43 - VANNUCCHI H et al. Amino acids patterns in the plasma and ascitic fluid of cirrhotic patients. Braz $\mathbf{J}$ Med Biol Res 18: 465-470, 1985. 
44 - VANNUCCHI H et al. Avaliação antropométrica e bioquímica do estado nutricional. Rev Med HCFMRP - USP Carl, 17: 17-28, 1984.

45 - VANNUCCHI H et al. Arm fat Index as an alternative parameter in the assessment of nutritional status of hospitalized patients J Nutr Med 3: 31 - 34, 1992.

46 - VANNUCCHI $\mathrm{H}$ et al. Assessment of zinc nutritional status of Pellagra patients. Alcohol Alcohol 30: 297-302, 1995.

47 - WATERLOW JC \& HARPER AE. In: GHADIMI H, ed. Total parenteral nutrition: Premises and promises. Willie, London, p. 231, 1975.
48 - WEINSER RL et al. Hospital malnutricion. A prospective evaluation of general medical patients during the course of hospitalization. Am J Clin Nutr 32:418-426, 1979.

49 - WHITEHEAD RG. Hydroxiproline creatinine ratio as an Index of nutritional status and rate of growth. Lancet 2: 567, 1965.

50 - WINBORN AL et al. A protocol for nutricional assessment in a community hospital. J Am Diet Assoc 78:129, 1981.

51 - YOUNG VR \& MUNRO HN Nt methylhistidine (3methylhistidine) and muscle protein turnover: An overview. Fed Proc 37:2291, 1978.

Recebido para publicação em 04/03/96

Aprovado para publicação em 14/03/96 